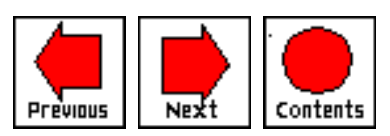

\title{
VIRTUAL ENVIRONMENTS FOR ARCHITECTURAL WALKTHROUGH: THREE APPLICATIONS
}

\author{
S. A. Stansfield $\{\{$ bio $\}\}$ \\ Sandia National Laboratories \\ Albuquerque, NM
}

Editor: Hal Thwaites

\section{ABSTRACT}

This paper presents a review of three virtual environments (VE) for architectural walkthrough currently available within the Virtual Reality/Intelligent Simulation Laboratory at Sandia National Laboratories. The applications for which these VEs were designed are discussed and a brief description of the modeling procedures is presented.

\section{Introduction}

Sandia National Laboratories has explored the development of virtual environments (VE) for architectural walkthrough within several projects. The application of these VEs is as varied as the projects themselves, ranging from facility design to public relations. This paper presents three of these VEs and briefly discusses their development and application. Each of the VEs described below has been ported to the facilities of Sandia's Virtual Reality/Intelligent Simulation Laboratory and may be viewed on any of several immersion VR devices, including the Fakespace BOOM3C (TM) viewer (shown in Figure 1) and the Virtual Research EyeGen3 (TM) headmounted display.

\section{Three Architectural Walkthroughs}

\subsection{MRS: DESIGN, SIMULATION AND ANALYSIS}

The Monitored Retrievable Storage (MRS) walkthrough is a virtual environment 
created in order to perform cost analyses and radiation exposure studies for a proposed civilian radioactive waste management system [2]. To reduce human exposure to radiation, it has been proposed that robots be used to automatically handle receiving and storing/transport of spent nuclear fuel within the facility. The VE created for this work is based upon conceptual design studies. It contains models of both the facility layout and the robots that might be used for the automated handling tasks. The VE is implemented and executed using Deneb Robotics IGRIP (TM) software. IGRIP (TM) accurately models the kinematics of the robotic devices. This allows realistic modeling of process flow and throughput for the virtual facility.

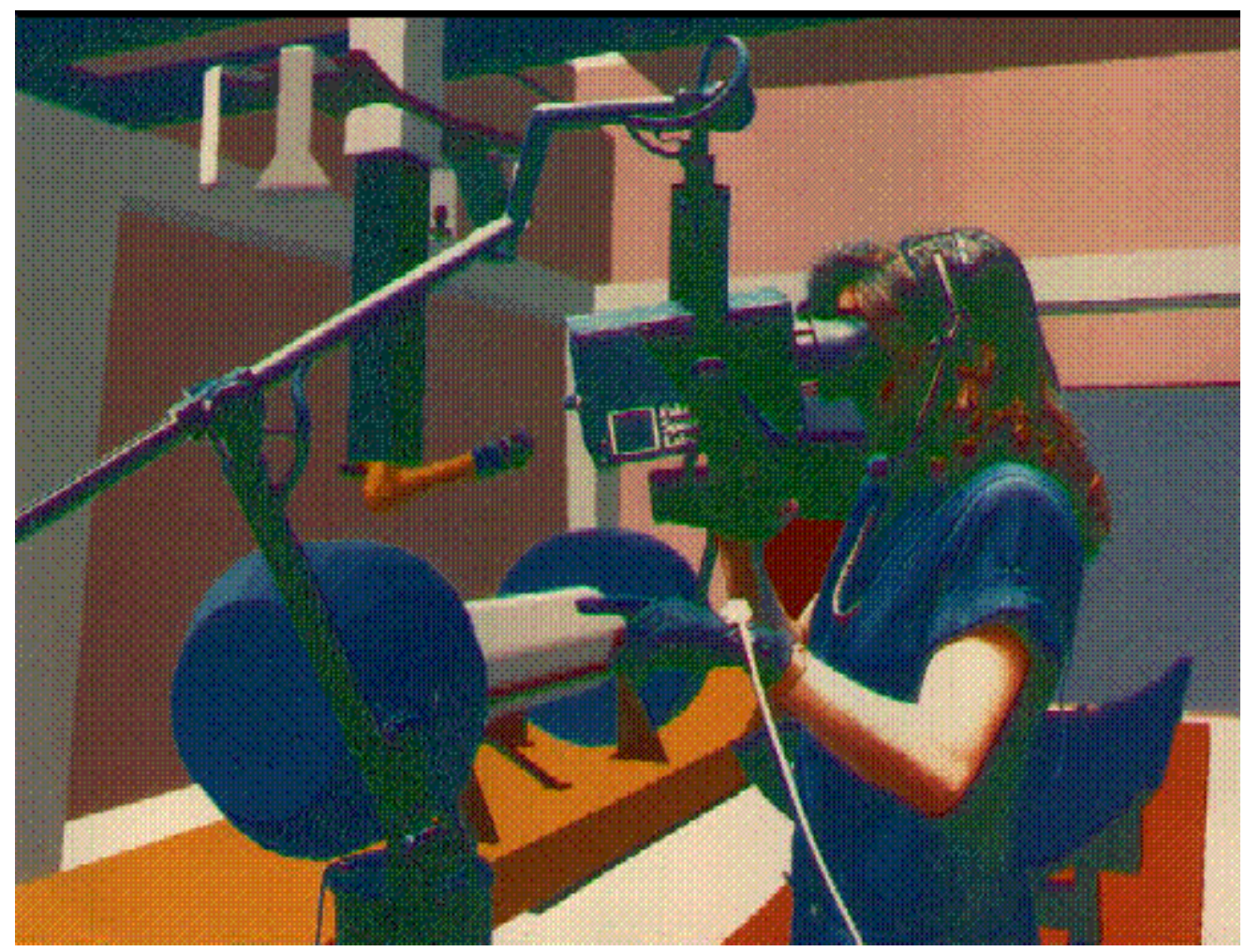

Figure 1: The Fakespace BOOM3C viewer.

The VE contains four major areas and several different robotic devices. Figure 2 shows one view of the MRS VE. The MRS walkthrough is used to do timing studies (related to radiation exposure) and cost analyses for the automated vs. manually-handled facility. The user, using the VR viewer, may walk through the facility while the simulated robots are carrying out their tasks, allowing him/her to visualize not only the space but the process flow as well. 


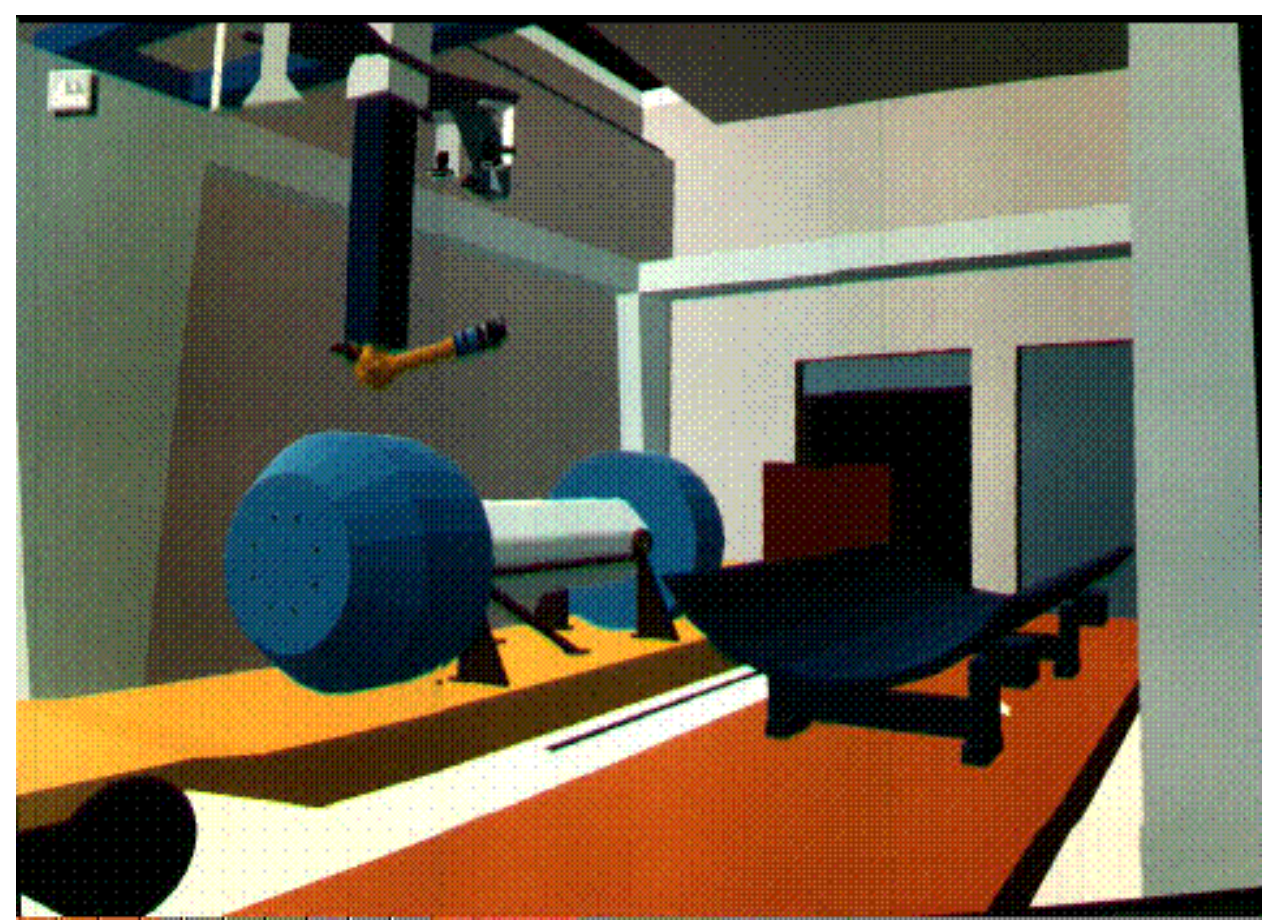

Figure 2: View of the MRS virtual environment.

\subsection{WIPP: PUBLIC RELATIONS AND VISUALIZATION}

The Waste Isolation Pilot Plant (WIPP) walkthrough is a VE initially created for public relations applications [1]. The WIPP itself is an underground facility near Carlsbad, New Mexico. It serves as a site to develop and demonstrate techniques for safe encapsulation and isolation of low-level radioactive waste, and will eventually become a repository for such waste. The facility is a large complex located approximately 2,100 feet under the ground. It consists of a series of storage rooms, shops, and experimental areas, connected by passageways. These spaces are carved out of an extensive, natural salt formation. The VE created for this work is based upon several different sources, including 2D CAD drawings of the floor plan, maps and annotated drawings, photographs, and visits to the actual site. Model creation was done in three steps. First a 3D volume was generated and iso-surfaces were calculated. Then the Marching Cubes algorithm was used to filter the volume data in order to round and blend surfaces. Finally, lighting and surface texture effects were added.

Textures are software-generated, with irregularities added manually using a paint program. This creates the patterns visible in the salt as the tunnels are carved out. Figure 3 shows one view of the WIPP VE. The WIPP walkthrough was originally created for public relations purposes, to allow simulated tours of the facility in anticipation of restricted access to the actual site due to storage of radioactive waste. The VE has subsequently also been used for visualization of air flow within the facility during emergency events, such as fire. 


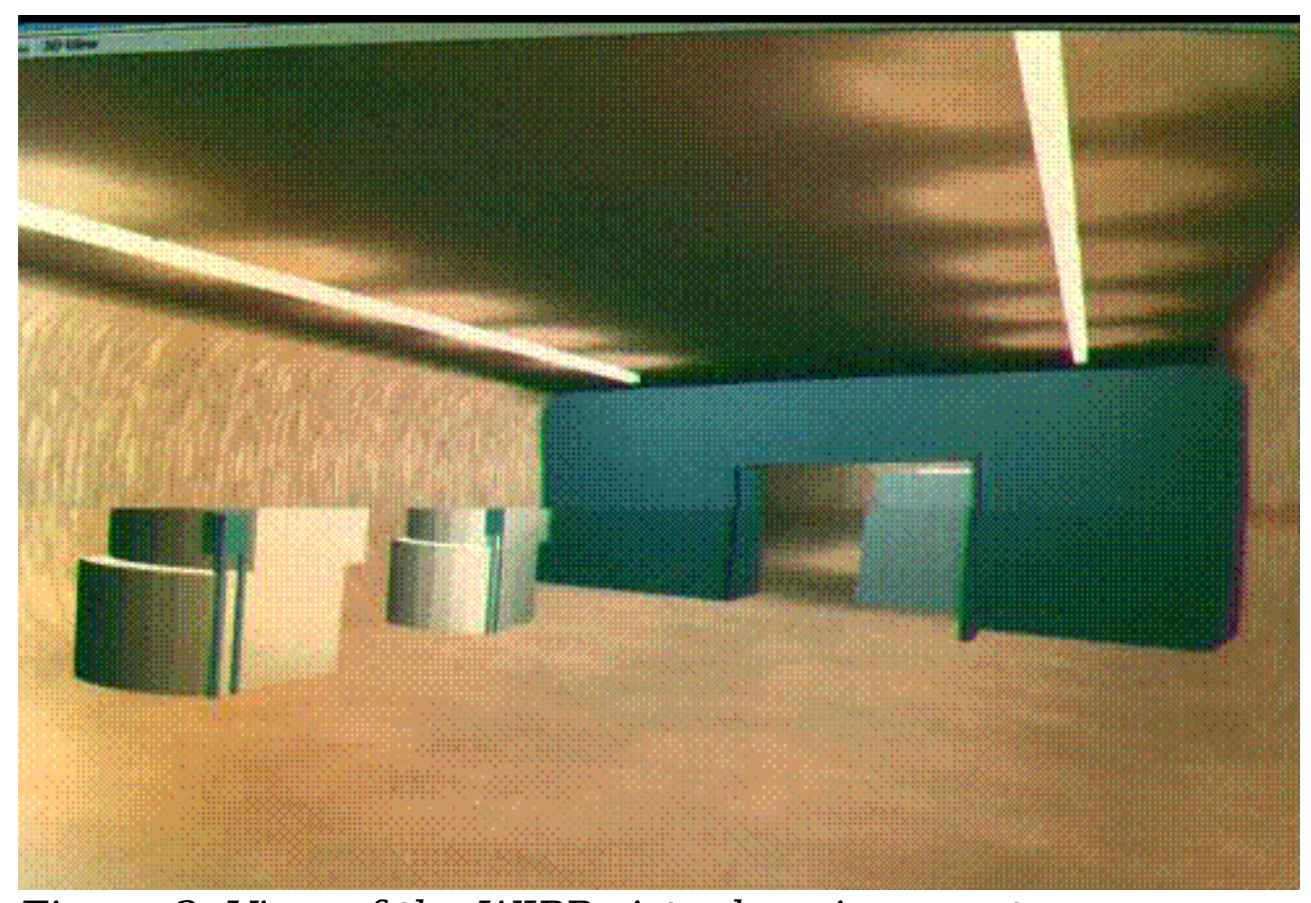

Figure 3: View of the WIPP virtual environment.

\subsection{HOT CELL: TRAINING}

The hot cell walkthrough is a VE created as part of an on-going research effort in applying virtual reality to situational training [3]. The facility, which is part of Sandia National Laboratories' Reactor Engineering Technology Center, is used to carry out radiation experiments. It consists of several labs and a series of shielded hot cells where the actual experiments are performed. Robotic Master/Slave devices allow experimenters to handle radioactive materials within the cells remotely. The hot cell walkthrough was created in three steps. In step one, the basic architecture was created from actual blueprints using Alias Designer (TM). A visit to the facility was then conducted, and a video was made providing comprehensive coverage of the areas to be modeled. In step two, this video was used to model and place other structural details, such as overhead piping, as well as furnishings, such as instrument racks, lab tables, etc. In step three, the same video was used to create texture maps for walls, floors, signs, instrument dials, and so on. These textures were taken from the digitized video, manually processed using a paint program, and then applied to the hot cell model. Figure 4 shows one view of the hotcell VE. 


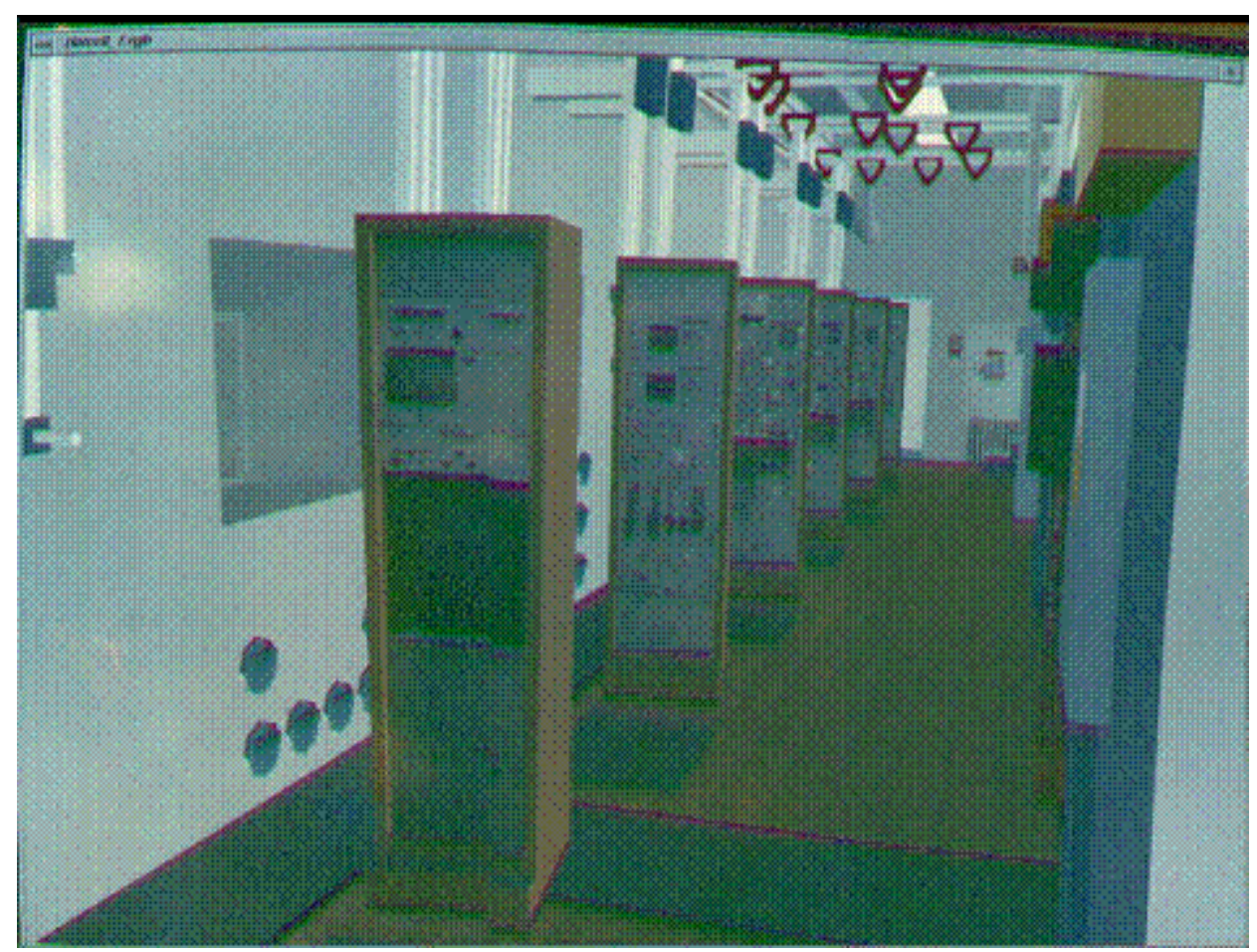

Figure 4: View of the hot cell virtual environment

The hot cell was chosen for this work because it is a facility subject to inspection under non-proliferation treaty verification: Non-proliferation treaties often provide for facility inspection to allow verification of compliance. Because the treaties provide for limited time within the facility, it is essential that both domestic inspectors of foreign facilities and escorts of foreign inspectors of U.S. sites have a high degree of familiarity both with the facility and with the procedures involved. Because these facilities are often both highly secure and hazardous, access to them is very limited. The hot cell walkthrough is one component of a virtual reality training system that is intended to be used to familiarize inspectors and escorts with such facilities by allowing them both to visualize the actual facility and to practice required procedures.

\section{ACKNOWLEDGMENTS}

The work described in this paper is the product of many talented people. In addition to the researchers referenced in the bibliography, we would like to gratefully acknowledge the contributions of Lisa Desjarlais, Dan Shawver, Dave Rogers, and Lydia Tapia. Thanks to them and to anyone whose contribution I might have inadvertently omitted. The work was performed at Sandia National Laboratories and was supported by the U.S. Department of Energy under Contract DE-AC04-94AL85000. Initial development of the WIPP model was supported by the New Mexico Waste-Management Education and Research Consortium. 

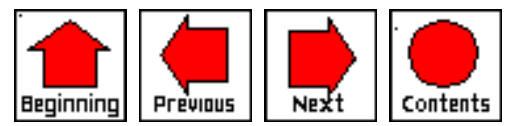

\section{REFERENCES}

[1] Angel, E., Thompson, F., Ferrara, A. and VanDyke, J., "Design of Operator Interfaces for Hazardous Waste Removal Systems," Radioactive Waste Management and the Nuclear Fuel Cycle, 1993. \{ \{ Return\}\}

[2] Bennet, P. and Stringer, J., "MRS/MPC Analysis: Simulation and Economics of Automation", presented at the 1994 (5th) International Conference on High Level Radioactive Waste Management, Las Vegas, NV, May, 1994. \{ \{Return\}\}

[3] Stansfield, S., Miner, N., Shawver, D. and Rogers, D., "An Application of Shared Virtual Reality to Situational Training", Proceedings of the IEEE Virtual Reality Annual International Symposium, March, 1995. \{\{Return\}\}

\section{BIOGRAPHY}

Dr. Sharon Stansfield received her Ph.D. in Computer Science from the University of Pennsylvania in 1987. She has been a Senior Member of Technical Staff at Sandia National Laboratories since 1988. Dr. Stansfield has performed research in such diverse areas as machine intelligence, cognitive models of robotic perception, and medical image interpretation.

In 1991, she established the Virtual Reality/ Intelligent Simulation Laboratory at Sandia. Funded research projects within this laboratory have included multiplayer, distributed VR for situational training applied to battlefield medicine, law enforcement, and robot operation in hazardous environments; VR-based hyper-media navigation; virtual humans and their behaviors, and development of real-time Avatars. Dr. Stansfield is a member of several professional societies and has numerous publications. She is the General Chair for the 1997 IEEE Virtual Reality International Symposium.

Contact information:

Sharon Stansfield

Sandia National Laboratory

PO Box 5800, MS 0978

Albuquerque, NM 87185-0978

Phone: 505-844-1396

FAX: 505-844-2057

Email: sastans@sandia.gov \{\{Return\}\} 


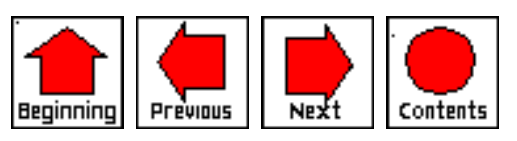

